\title{
Representasi Anak Muda Gaul dan Saleh dalam Gerakan Hijrah: Analisis Semiotika Roland Barthes atas Konten Akun Instagram Pesan Trend Pemuda (@pesan_trend)
}

\author{
Muhamad Ibtissam Han \\ Fakultas Dakwah, Institut PTIQ Jakarta, Indonesia \\ email: mibtissamhan@ptiq.ac.id
}

\begin{abstract}
The stagnation of da'wah among young people is mostly caused by the use of symbols that are not in line with or even contrary to the aspirations of young people. The da'wah offered by the Hijrah Youth Shift Movement is a da'wah that uses symbols of young people as a medium for their da'wah. This article tries to explain how the Hijrah Youth Shift Movement represents the value of young people who are slang and pious. Through Rolland Barthes' semiotic approach, the author tries to examine these symbols which are presented in the da'wah content uploaded to the Instagram $@$ message_trend account. In denotation, posts from the Instagram @message_trend account display activities such as cleaning, archery, camping, tahajud prayer in green open spaces. In connotation, the Instagram account @pesan_trend tries to show a model of young Muslim people who love the environment, are physically and spiritually healthy. Mythically or ideologically, @pesan_trend, which was initiated by UHA and Shift Pemuda Hijrah, is showing the social class of middle-class Muslim youth, which so far has been identified with indie culture, which is active in green spaces. On the other hand, this also shows the ideology of Shift which is leaning towards the tarbiyah movement.
\end{abstract}

\section{Keywords:}

Youth Da'wah, Hijrah, Instagram, Semiotics, Roland Barthes

\begin{abstract}
Abstrak
Stagnasi dakwah di kalangan anak muda banyak disebabkan oleh penggunaan simbol-simbol yang tidak sejalan atau bahkan bertentangan dengan aspirasi anak muda. Dakwah yang ditawarkan Gerakan Shift Pemuda Hijrah adalah dakwah yang memanfaatkan simbol-simbol anak muda sebagai media dakwah mereka. Artikel ini mencoba untuk menjelaskan bagaimana Gerakan Shift Pemuda Hijrah
\end{abstract}


merepresentasikan nilai anak muda yang gaul dan saleh. Melalui pendekatan semiotika Rolland Barthes, penulis mencoba menelisik simbol-simbol tersebut yang disajikan dalam konten dakwah yang diunggah pada akun Instagram @pesan_trend. Secara denotasi kiriman dari akun Instagram @pesan_trend menampilkan kegiatankegiatan seperti bersih-bersih, memanah, camping, salat tahajud di alam terbuka hijau. Secara konotasi akun Instagram @pesan_trend mencoba menampilkan model anak muda muslim yang cinta akan lingkungan, sehat secara jasmani dan juga rohani. Secara mitos atau ideologis @pesan_trend yang digagas oleh UHA dan Shift Pemuda Hijrah sedang menunjukkan kelas sosial anak muda muslim kelas menengah yang selama ini banyak diidentikkan dengan budaya indie yang banyak beraktivitas di alam terbuka hijau. Di sisi lain hal tersebut juga menunjukkan ideologi Shift yang berhaluan gerakan tarbiyah.

\section{Kata Kunci:}

Dakwah Anak Muda, Hijrah, Instagram, Semiotika, Rolland Barthes

\section{Pendahuluan}

Dalam dekade terakhir isu hijrah menjadi bahan perbincangan oleh kalangan anak muda di jagat maya. Namun yang menarik dari fenomena hijrah saat ini adalah munculnya gerakan-gerakan hijrah yang tidak lagi berpaku pada simbol-simbol islami sebagaimana yang muncul pada gerakan hijrah awal 2000-an. ${ }^{1}$ Para penggiat dakwah di kalangan anak muda datang membawa simbol-simbol yang justru lahir dari budaya anak muda, yang terdiri dari berbagai subkultur. Para dai pun tampil tidak menggunakan pakaian sebagaimana dai pada umumnya, tetapi dengan atribut kemudaan seperti topi kupluk dan kemeja flannel. ${ }^{2}$

Hal tersebut tidak bisa dilepaskan dari peran gerakan dakwah di kalangan anak muda, dan lebih dikerucutkan akan mengarah kepada gerakan dakwah Shift Pemuda Hijrah. Gerakan ini selain diterima oleh banyak anak muda muslim di Bandung, yang dibuktikan dengan setiap kajiannya selalu dipadati oleh ribuan anak

\footnotetext{
${ }^{1}$ Pada masa itu gerakan keislaman muncul dengan simbol-simbol seperti banyaknya pemuda yang mengenakan jalabiyah (jubah panjang), imamah (serban), isbal (celana yang panjangnya hanya sampai mata kaki) dan lihyah (jenggot panjang)

${ }^{2}$ Muhamad Ibtissam Han, Dakwah Jalanan Kaum Muda: Dinamika Keagamaan Anak Muda Genk Motor dan Skateboard (Yogyakarta: Diandra Kreatif dan Penerbit Omah ilmu, 2019), 4.
} 
Representasi Anak Muda Gaul dan Saleh dalam Gerakan Hijrah: Analisis Semiotika Konten Akun Instagram Pesan Trend Pemuda (@pesan_trend)

muda yang hadir secara luring maupun daring melalui platform digital juga banyak menginspirasi lahirnya gerakan-gerakan dakwah serupa di kalangan anak muda Bandung. ${ }^{3}$

Selain itu fenomena gerakan dakwah di kalangan anak muda pun banyak menarik perharian para sarjana. Mereka yang mengkaji mengenai gerakan dakwah di kalangan anak muda menekankan pada bagaimana dakwah menggunakan produkproduk atau perangkat-perangkat budaya populer seperti majalah, ${ }^{4}$ sastra, ${ }^{5}$ musik, ${ }^{6}$ sinetron ${ }^{7}$ sampai media sosial. ${ }^{8}$ Triantoro menyebutkan bahwa praktik dakwah dengan memanfaatkan majalah membuat agama Islam menjadi lebih dinamis dan dapat berjalan beriringan (hand in hand) dengan perkembangan budaya populer. ${ }^{9}$ Dan hal itu dapat terjadi karena kemampuan para penggiat dakwah pesan-pesan keagamaan yang sebelumnya rigid dan kaku menjadi lebih sesuai dengan aspirasi anak muda muslim. ${ }^{10}$

\footnotetext{
${ }^{3}$ Han, Dakwah Jalanan Kaum Muda: Dinamika Keagamaan Anak Muda Genk Motor dan Skateboard, 40,53,7377.

${ }^{4}$ Noorhaidi Hasan, "The Making of Public Islam: Piety, Agency, and Commodification on the Landscape of the Indonesian Public Sphere," Contemporary Islam 3, no. 3 (Oktober 2009): 229-50, https://doi.org/10.1007/s11562-009-0096-9; Dony Arung Triantoro, "D’RISE Magazine: Between The Piety, Popular Culture And Ideology,” 2018, 31-40.

${ }^{5}$ Najib Kailani, "Forum Lingkar Pena and Muslim Youth in Contemporary Indonesia," Review of Indonesian and Malaysian Affairs 46, no. 1 (2012): 33-53; Eva F. Nisa dan Monika Arnez, "Dimensions of Morality: The Transnational Writers' Collective Forum Lingkar Pena," Bijdragen Tot de Taal-, Land- En Volkenkunde/ Journal of the Humanities and Social Sciences of Southeast Asia 172, no. 4 (1 Januari 2016): 449-78, https://doi.org/10.1163/22134379-17204003; Akh. Muzakki, "TRANSMITTING ISLAM THROUGH STORIES: The Sociology of Production and Consumption of Islam in Novel Literature," JOURNAL OF INDONESIAN ISLAM 11, no. 1 (6 Juli 2017): 59, https://doi.org/10.15642/JIIS.2017.11.1.59-76.

${ }^{6}$ Margaret Sarkissian, "Religion Never Had It so Good': Contemporary Nasyid and the Growth of Islamic Popular Music in Malaysia," Yearbook for Traditional Music 37 (2005): 124-52; Kamaludeen Mohamed Nasir, Globalized Muslim Youth in the Asia Pacific: Popular Culture in Singapore and Sydney, The Modern Muslim World (Basingstoke: Palgrave Macmillan, 2016).

${ }^{7}$ Inaya Rakhmani, Mainstreaming Islam in Indonesia (New York: Palgrave Macmillan US, 2016), https://doi.org/10.1057/978-1-137-54880-1.

${ }^{8}$ Muhammad Ibtissam Han, "Ustadz Hits: Bahasa Gaul dan Social Media Effect," dalam Islam: Antara Teks, Kuasa dan Identitas, ed. oleh Sunarwoto (Yogyakarta: Arti Bumi Intaran, 2018), 163-81; Eva F. Nisa, "Creative and Lucrative Da 'wa: The Visual Culture of Instagram amongst Female Muslim Youth in Indonesia," Asiascape: Digital Asia 5, no. 1-2 (14 Februari 2018): 68-99, https://doi.org/10.1163/22142312-12340085; Han, Dakwah Jalanan Kaum Muda: Dinamika Keagamaan Anak Muda Genk Motor dan Skateboard.

${ }^{9}$ Triantoro, "D’RISE Magazine: Between The Piety, Popular Culture And Ideology," 39.

${ }^{10}$ Najib Kailani, "Perkembangan Literatur Islamisme Populer di Indonesia: Apropriasi, Adaptasi dan Genre," dalam Literatur Keislaman Generasi Milenial: Transmisi, Apropriasi, dan Kontestasi, ed. oleh Noorhaidi Hasan (Yogyakarta: Pascasarjana UIN Sunan Kalijaga Press, 2018), 144-45.
} 
Jika melihat dari perkembangan gerakan dakwah di kalangan anak muda, upaya-upaya mengakomodasi aspirasi-aspirasi anak muda muslim sudah dilakukan sejak generasi-generasi awal, yakni pada gerakan awal dakwah kampus yang dipelopori oleh Imaduddin Abdulrahim dengan Masjid Salman ITB pada tahun 1970an. ${ }^{11}$ Gerakan tersebut kemudian dianggap oleh salah satu pengikut Bang Imad, yaitu Toto Tasmara, terlalu fokus pada mahasiswa. Dia kemudian mengagas gerakan dakwah yang tidak hanya menjangkau mahasiswa tetapi juga pelajar dengan mendirikan Badan Komunikasi Pemuda Masjid Indonesia (BKPMI) di Masjid Istiqomah Bandung pada tahun 1979.12

Dalam pandangan Hanan Attaki, gerakan-gerakan dakwah di kalangan anak muda saat ini mengalami stagnansi yang luar biasa. Jamaah yang hadir dalam sebuah pengajian adalah mereka yang selama ini sudah aktif dalam gerakan dakwah atau memiliki latar belakang Rohis ketika di sekolahnya. Sedangkan anak muda muslim yang berada dalam zona tersebut hanya lah minoritas dari anak-anak muda yang lebih aktif dalam dunia subkultur, yang selama ini belum banyak dirangkul oleh gerakan dakwah. Semangat itulah yang melahirkan gerakan Shift Pemuda Hijrah yang mengusung konsep dakwah jalanan (street dakwah). ${ }^{13}$ Dalam bahasanya Inong, salah satu pencetus Shift, anak muda muslim terbagi menjadi empat kelompok, yaitu: pertama, mereka yang sudah aktif dalam gerakan dakwah seperti LDK, Rohis dll.; kedua, mereka simpatisan dakwah; ketiga mereka yang acuh tak acuh; dan terakhir mereka yang kontra dan anti terhadap gerakan dakwah. Kelompok yang ketiga dan keempat ini lah yang menjadi konsentrasi dari gerakan Shift, atau yang sering disebut sebagai ‘anak main'. ${ }^{14}$

\footnotetext{
${ }^{11}$ Robert W Hefner, Civil Islam: Muslims and Democratization in Indonesia, Princeton studies in Muslim politics (Princeton: NJ: Princeton University Press, 2000), 123; Rifki Rosyad, A Quest for True Islam: A Study of the Islamic Resurgence Movement among the Youth in Bandung, Indonesia (ANU E Press, 2007), 23.

${ }_{12}^{12}$ Rosyad, A Quest for True Islam, 40-41.

${ }^{13}$ Han, Dakwah Jalanan Kaum Muda: Dinamika Keagamaan Anak Muda Genk Motor dan Skateboard, 4.

${ }^{14}$ Wahyudi Akmaliah, "THE RISE OF COOL USTADZ: PREACHING, SUBCULTURES AND THE PEMUDA HIJRAH MOVEMENT," dalam The new Santri: challenges to traditional religous authority in Indonesia (Singapore: ISEAS Publishing, 2020), 247.
} 
Representasi Anak Muda Gaul dan Saleh dalam Gerakan Hijrah: Analisis Semiotika Konten Akun Instagram Pesan Trend Pemuda (@pesan_trend)

Kemudian permasalahan yang dihadapi untuk mendekati 'anak main' yaitu adanya stereotip di antara mereka bahwa untuk menjadi saleh mereka akan kehilangan identitas kemudaannya. Mereka beranggapan bahwa pergi ke masjid akan membuat mereka menjadi kuuleun (kampungan), sehingga mereka pada akhirnya enggan untuk mengikuti pengajian di masjid. Selain itu penampilan para ustaz yang mengenakan simbol-simbol keislaman seperti jalabiyah (jubah panjang), imamah (serban), isbal (celana yang panjangnya hanya sampai mata kaki) dan lihyah (jenggot panjang), dianggap terlalu kaku dan menakutkan. ${ }^{15}$ Hal tersebut membuat gerakan Shift mencoba mengadopsi dan menggunakan simbol-simbol budaya populer tidak hanya pada pakaian para ustaz juga pada poster-poster kajian yang mereka unggah ke media sosial.

Tidak selesai di situ penggunaan simbol subkultur anak muda yang dilakukan oleh Shift pun tidak sepenuhnya diterima oleh semua genre subkultur anak muda Muslim di Kota Bandung. Karena setiap genre subkultur memiliki definisinya masing-masing. Acap kali sebuah poster yang dianggap keren oleh satu genre justru dianggap tidak menarik bagi genre lainnya. Misalnya poster kajian yang bertuliskan Keep The Feith, nama album Bon Jovi, menggunakan font Seek $n$ Destroy milik Mettalica. Ketika poster tersebut muncul di beranda media sosial, orang-orang yang tertarik kemungkinan besar adalah mereka yang berasal dari genre musik-musik keras. Tapi bagi kelompok yang lain, mungkin elemen-elemen itu terasa mengganggu dan tidak menarik. $^{16}$

Ihwal ketidakmampuan dalam mengakomodasi semua aspirasi dari berbagai genre subkultur anak muda tersebut, pada awal 2019 Shift membuat gebrakan baru yang diberi nama Pesan Trend Pemuda. Dalam kiriman pertamanya di Instagram, Ustaz Hanan Attaki (UHA) mengajak para pengikutnya untuk mewujudkan sebuah

\footnotetext{
${ }^{15}$ Han, Dakwah Jalanan Kaum Muda: Dinamika Keagamaan Anak Muda Genk Motor dan Skateboard, 30-31.

${ }^{16}$ Han, Dakwah Jalanan Kaum Muda: Dinamika Keagamaan Anak Muda Genk Motor dan Skateboard, 55.
} 
kawasan yang menjadi berkumpulnya anak muda lintas genre dan komunitas. Tempat yang pantas untuk mereka berkarya, beribadah, dan belajar.

“Di kawasan @pesan_trend seluas 3 hektar itu kita bisa cetak pemuda2 \#taattapiasik \#gaultapisoleh . Dimana masjid, kafe, studio kreatif, dan area workout utk maen, bisa jadi pusat kegiatan anak muda utk beraktifitas \& berinteraksi. Tempat ini adalah milik kita bersama, menjadi harapan untuk masa depan generasi emas Indonesia. Saya @hanan_attaki pengasuh \#pesan_trend Pemuda, yuk selamatkan Indonesia dari radikalisme, sex bebas, dan narkoba \#indonesiakeren \#respect"

Singkatnya, gebrakan terbaru dari Shift Pemuda Hijrah yang bernama Pesan Trend Pemuda ini mencoba menawarkan konsep dakwah kepada anak muda yang tidak hanya terikat oleh satu dua simbol genre subkultur tertentu namun tetap mengedepankan nilai keislaman yang dibalut dengan simbol-simbol budaya populer. Menurut Ariel Heryanto, budaya populer dapat dimaknai dengan dua cara. Pertama, budaya populer berarti segala bentuk suara, gambar, dan pesan yang diproduksi secara massal dan komersil dalam berbagai bentuk seperti busana, musik, film dan acara televisi, untuk menjangkau sebanyak mungkin massa, sebagai konsumen dari industri. Sedangkan definisi lainnya menekankan budaya populer sebagai praktik komunikasi yang secara independent beredar memanfaatkan berbagai forum dan peristiwa seperti acara keramaian publik, parade dan festival. ${ }^{17}$

Mengacu pada definisi mengenai budaya populer di atas, kita dapat melihat bahwa konten dakwah yang dibuat oleh Shift Pemuda Hijrah di akun Instagramnya merupakan produk budaya populer yang dapat dibaca melalui pendekatan semiotika. Dalam hal ini Merlyna Lim menjelaskan bahwa infrastruktur media sosial yang membangun hubungan yang lemah (weak ties) antara para pengguna, menuntut

\footnotetext{
${ }^{17}$ Ariel Heryanto, Identitas dan Kenikmatan: Politik Budaya Layar Indonesia (Jakarta: Kepustakaan Populer Gramedia, 2015), 21-22.
} 
pembuat pesan mampu membingkai pesan dengan narasi yang sederhana dan juga bersifat ikonik. ${ }^{18}$

Dari pemaparan tersebut peneliti mencoba untuk menjawab beberapa pertanyaan besar yakni bagaimana gerakan Shift Pemuda Hijrah merepresentasikan nilai anak muda yang gaul dan saleh. Pertanyaan tersebut akan dijawab melalui pertanyaan-pertanyaan minor: pertama, bagaimana makna dentotasi dari kontenkonten akun Instagram @pesan_trend; kedua, bagaimana makna konotasi dari konten-konten akun Instagram @pesan_trend; terakhir, apa makna idiologi atau mitos yang ada di balik konten-konten akun Instagram @pesan_trend.

\section{Pendekatan Semiotika}

Menurut Gill Branston dan Roy Stafford, secara garis besar dalam memahami teks media terdapat dua mazhab besar. Pertama, pendekatan yang mewakili metode kualitatif yaitu semiotika, dengan menggali kualitas-kualitas teks-teks media secara mendalam. Pendekatan kedua yaitu pendekatan kuantitatif dengan metode analisis konten yang menggali teks media melalui kemungkinan adanya repetisi pola pada elemen-elemen teks. Kedua pendekatan tersebut berbeda secara metodologi, namun dapat berguna saat digunakan bersamaan, di mana masing-masing menghadirkan bagian terpenting dari yang dapat mereka sajikan. ${ }^{19}$ Dalam hal ini pemakalah hanya akan fokus pada satu pendekatan yaitu pendekatan semiotika.

Semiotika adalah studi terhadap tanda/lambang (signs), bagaimana lambanglambang tersebut memproduksi maknanya, atau studi mengenai bagaimana sesuatu memiliki signifikansi. Di kurun waktu terakhir, semiotika juga disebut Semiotika

\footnotetext{
${ }^{18}$ Merlyna Lim, "Many Clicks but Little Sticks: Social Media Activism in Indonesia," Journal of Contemporary Asia 43, no. 4 (November 2013): 636-57, https://doi.org/10.1080/00472336.2013.769386.

19 Gill Branston dan Roy Stafford, The Media Student's Book, Fifth (Routledge, 2010), 9-11, https://doi.org/10.4324/9780203850640.
} 
Sosial. Studi ini dipengaruhi oleh Ferdinan de Saussure, Charles Sanders Pierce dan Roland Barthes. Saussure berpendapat bahwa sebuah lambang mengandung bentuk penanda fisik/physical signifier (gestur, tulisan di atas kertas, lambing musik) serta bentuk immateri dari yang ditandakan/immaterial signified, atau ide yang melekat terhadap penanda-penanda fisik. Demikian juga dengan kata-kata. Saussure berpendapat bahwa kata-kata sebagai penanda berbentuk verbal (verbal signifiers), memiliki relasi terhadap ide yang lahir dan melekat dengan kata-kata tersebut (signifieds). Gambaran mengenai bunga yang kita pikirkan saat membaca maupun mendengar kata B-U-N-G-A misalnya, merupakan ide yang melekat dengan kata tersebut. Signifier dan signified adalah dua konsep utama semiotika. Oleh karenanya menurut semiotika, persepsi kita mengenai realitas pada dasarnya dikonstruksi dan dibentuk melalui kata-kata dan lambang-lambang yang kita gunakan. Saussure juga berpendapat bahwa Bahasa merupakan hasil kreasi budaya dan tidak hadir secara alami.

Sementara itu Pierce berpendapat lebih jauh, dengan membawa sebuah istilah yang disebut the referent, atau sesuatu yang dirujuk oleh signifier dan signified, yaitu bentuk nyata dari benda yang dibicarakan. Konsepsi ini semakin menunjukan bahwa signified adalah konsep yang terbentuk secara kultural. Bila kata ataupun suara B-UN-G-A adalah signifier dan ide mengenai gambaran bunga dalam pikiran kita adalah the signified, maka 'bunga asli' yang kita lihat adalah the referent. Pierce juga berpendapat ada 3 jenis dari lambang, yaitu: simbol, ikon dan indeks, yang ditentukan oleh relasi antara lambang dan maknanya. Bila jenis hubungan antara signifier dan signified bersifat lepas dan tidak ada kaitannya, contohnya seperti Bahasa, maka disebut simbol. Bila lambang tersebut mengisyaratkan secara langsung apa yang digambarkan, seperti gambar bunga, foto bunga, atau emotikon berbentuk bunga, maka disebut ikon. Bila hubungan antara lambang dan yang dilambangkan berupa kasualitas, maka disebut indeks. Contoh: asap menjadi penanda dari api. Dalam 
praktiknya, tentu tiga jenis lambang ini sering kali dikombinasikan dalam busana, arsitektur, dsb. ${ }^{20}$

\section{Sktrukturalisme}

Stukturalisme adalah gagasan yang mengalir menjadi bagian dari semotika di mana secara umum memiliki dua posisi utama. Pertama, para pemikir abad 19 berpendapat bahwa tatanan sosial manusia ditentukan oleh struktur sosial maupun struktur psikologi yang besar yang melampaui independensi manusia secara individu. Hal ini seperti yang dikemukakan Sigmund Freud dan Karl Marx. Kedua, oleh karena sesuatu tidak lepas dari struktur yang menaunginya, demikian juga dengan makna. Makna bisa dipahami melalui relasi struktur sistemik yang melahirkannya. Dalam hal ini bisa dipahami bahwa masing-masing unit sosial masyarakat di dunia memiliki sistem dan kekhasannya tersendiri. ${ }^{21}$

\section{Denotasi dan Konotasi}

Setiap lambang mampu memiliki dua sifat, yaitu denotasi dan konotasi. Denotasi yaitu pengisyaratan secara langsung, seperti kata 'merah' yang mendenotasikan salah satu jenis spektrum warna yang membuatnya berbeda dengan biru dan hijau. Adapun konotasi adalah bagaimana sebuah lambang memiliki kaitan dengan hal lain, bisa dengan konsep budaya, nilai, pengalaman, maupun perasaan emosional. ${ }^{22}$

\section{Sifat Sosial dari Lambang}

Sebagaimana dijelaskan sebelumnya, setiap lambang memiliki elemen sosial di dalamnya. Semiotika hadir dan sangat berguna dalam memikirkan ulang proses produksi makna dalam sosial. Ada beberapa poin yang perlu dicatat mengenai ini: Pertama, lambang bukan hal yang tetap (fixed), namun bersifat polisemik atau mampu

\footnotetext{
${ }^{20}$ Branston dan Stafford, The Media Student's Book, 11-18.

${ }^{21}$ Branston dan Stafford, The Media Student's Book, 18-21.

${ }^{22}$ Branston dan Stafford, The Media Student's Book, 21-23.
} 
memiliki beberapa arti dan asosiasi dalam waktu bersamaan. Memahami sifat naluriah lambang yang memiliki makna ganda, maka tentu terjadi upaya-upaya pengontrolan makna agar menjaga tidak adanya ambiguitas. Contohnya untuk keperluan berita dan periklanan. Proses penggaungan makna tertentu dari suatu lambang yang bertujuan untuk mengontrol makna ini dalam semiotika disebut anchoring. Kedua, setiap lambang dikontestasikan dan diperjuangkan oleh pihak yang memperoleh keuntungan dari hasil anchoring maupun re-anchoring. Dalam hal ini penting untuk melihat struktur kuasa dari setiap lambang. ${ }^{23}$

\section{Dakwah dengan Bahasa Kaumnya}

Untuk berdakwah setidaknya ada beberapa syarat yang harus dipenuhi, salah satunya adalah seorang pendakwah ( $\left.d a^{\prime} i\right)$ harus memahami audiensnya (mad'u). Hal ini sejalan dengan isryarat Al-Qur'an, surat Ibrahim ayat 4 yang berbunyi:

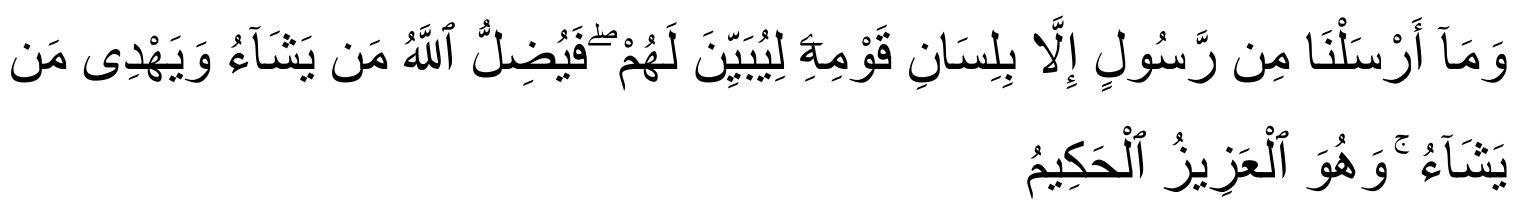

Artinya: "Kami tidak mengutus seorang rasulpun, melainkan dengan bahasa kaumnya, supaya ia dapat memberi penjelasan dengan terang kepada mereka. Maka Allah menyesatkan siapa yang Dia kehendaki, dan memberi petunjuk kepada siapa yang Dia kehendaki. Dan Dialah Tuhan Yang Maha Kuasa lagi Maha Bijaksana." (QS Ibrahim: 4)

Jika mengacu pada ayat di atas penggunaan bahasa, yang mencakup di dalamnya simbol-simbol, dalam proses berdakwah harus disesuaikan dengan bahasa yang digunakan oleh audiensnya. Dalam hal ini dakwah untuk kalangan anak muda maka bahasa yang digunakan pun harus menggunakan bahasa anak muda. Terlebih anak muda saat ini cukup aktif dan selektif dalam memilah-milah pesan termasuk pesan keagamaan yang sesuai dengan aspirasi mereka.

\footnotetext{
${ }^{23}$ Branston dan Stafford, The Media Student's Book, 23-25.
} 
Dalam era digital seperti sekarang ini, anak muda dapat disebut sebagai native adapter atau generasi yang sudah lahir di mana internet telah hadir. Cara mereka belajar, berbudaya, berbahasa, bersosial dan juga berpolitik sangat dipengaruhi oleh kehadiran internet. Di mana kesetaraan yang ditawarkannya membuat anak muda hidup dengan pandangan yang cenderung horizontal atau anti terhadap hierarki. ${ }^{24}$

Lebih jauh lagi ketika menjadi anak muda dan pada saat yang sama dia menjadi seorang Muslim, ia akan menemukan persoalan lain. Saat penanda keislaman menjadi penting, mereka memiliki cara sendiri dalam menampilkannya. Mereka menerjemahkan nilai-nilai keislaman dan mengartikulasikan kembali dengan cara mereka, yaitu cara yang mengakomodasi habitus mereka sebagai anak muda muslim. ${ }^{25} \mathrm{Hal}$ ini sejalan dengan teori 'Resepsi Aktif' yang disampaikan oleh Andi Faisal Bakti bahwa keefektifan sebuah komunikasi tidak dilihat dari komunikator dan pesannya saja tetapi bagaimana komunikan menerima itu. ${ }^{26}$ Dalam kasus ini Shift melalui gerakan Pesan Trend Pemuda mencoba mengakomodasi aspirasi dari komunikannya, yaitu para pemuda, agar dakwah lebih mudah diterima dan juga tujuan dakwah menjadi tercapai.

\section{Sejarah Lahirnya Shift Pemuda Hijrah}

Ustaz Hanan Attaki (UHA) adalah seorang penceramah kelahiran Aceh, 31 Desember 1981. Dia adalah alumni, jurusan tafsir Quran di Fakultas Ushuluddin Universitas Al Azhar, Kairo, Mesir. Di Mesir dia mendapatkan beasiswa dan beberapa kali mengikuti lomba tilawah Quran. Bahkan pada tahun 2005 dia menjadi qari

\footnotetext{
${ }^{24}$ Bayat dan Herrera, Being Young and Muslim: New Cultural Politics in The Global South and North, 10.

${ }^{25}$ Bayat dan Herrera, Being Young and Muslim: New Cultural Politics in The Global South and North, 19.

${ }^{26}$ Andi Faisal Bakti, "Raising Public Consciousness About the Importance of Freedom of Expression In Democratic Society and On Enhancing the Quality of Life of the Ordinary Citizen: the Case of Indonesia," The Journal of Development Communication 24, no. 1 (2013).
} 
terbaik versi Fajar TV, kemudian dia rutin mengisi acara tilawah Quran "Min Ajmalis Soth" (Dari Suara yang Indah) pada dua stasiun televisi, Fajar TV dan Iqra TV. ${ }^{27}$

Setelah pulang dari Mesir dia ikut bersama istrinya, Haneen Akira, tinggal di Jawa Timur. Pada tahun 2006, ketika Haneen mendapatkan pekerjaan di Kota Bandung, Hanan kemudian mengikuti istrinya tersebut, dan memutuskan untuk menjadi seorang penceramah di Kota Bandung. Mulai saat itu, UHA mengisi pengajian di Masjid Al Latif yang dikelola oleh pengurus masjid yang disebut dewan kemakmuran masjid (DKM) Masjid Al Lathiif, yang secara reguler mengundang UHA untuk mengisi pengajian keagamaan.

Setelah berjalan delapan tahun, Hanan merasa model pengelolaan dakwah seperti di Masjid Al Lathiif membutuhkan sentuhan inovasi. Menurutnya dakwah seharusnya dirancang oleh ustaz atau ulama yang memiliki visi misi dakwah yang jelas, dan DKM berlaku sebagai pendukung kegiatan. Pemikiran untuk mengemas ulang pengajian di Al Lathiif ini tidak hanya datang dari dirinya sendiri, tetapi juga dari jamaah rutinnya. Hanan bersama beberapa jamaah yang berjumlah enam orang, yang masing-masing memiliki keahlian salah satu di antaranya adalah Inong, seorang tokoh senior di dunia skateboarding, memikirkan gagasan untuk membuat gerakan dakwah yang mampu merangkul anak muda. Mereka secara bersama-sama mulai merumuskan nama gerakan, konsep dakwah, sampai segmentasi anak muda seperti apa yang akan menjadi target dakwah dan bagaimana pengelolaannya.

Dalam menentukan nama gerakan Shift Pemuda Hijrah, sejak awal mereka, para penggagas, berusaha untuk menghindari istilah hijrah. Mereka meyakini bahwa anak-anak muda tersebut masih alergi dengan kata-kata semacam hijrah dikarenakan adanya stigma di kalangan anak muda bahwa dengan berhijrah, seseorang akan

27 https://www.biografiku.com/2018/01/biografi-dan-profil-lengkap-ustazz-hanan-attaki-pendiri-pemudahijrah.html (diakses 20 Oktober 2020) 
menghilangkan unsur kesenangan (fun) dalam hidupnya, dan itu akan membuat anak muda lebih dahulu menolak ajakan dakwah.

\section{Pesan Trend Pemuda}

Pesan Trend Pemuda adalah sebuah kawasan yang diproyeksikan akan menjadi jantung peradaban anak muda Indonesia yang berdiri di atas lahan 3 hektare. Kawasan ini digagas langsung oleh UHA dan tim Shift Pemuda Hijrah. Kawasan ini juga diharapkan akan menjadi tempat menuntut ilmu yang sangat ramah bagi para pemuda, karena di dalam kawasan ini akan dibangun berbagai fasilitas untuk menunjang kreativitas para pemuda. ${ }^{28}$

Kawasan Pesan Trend Pemuda juga diharapkan bisa menjadi satu pusat kegiatan pemuda di Kota Bandung dan sekitarnya. Dalam segmentasi umum kawasan semacam ini biasa disebut dengan Islamic center, namun karena dakwah ini memiliki segmentasi anak muda maka mereka memberi nama Pesantren Pemuda. Dalam 24 jam kawasan tersebut akan diisi dengan berbagai macam aktivitas pendidikan baik pendidikan Islam, pendidikan tentang kesadaran sosial, karakter, moral dan lainnya termasuk pendidikan keterampilan sesuai kebutuhan anak muda.

Adapun tujuan dari Pesan Trend Pemuda ini di antaranya: Pertama, membangun pusat peradaban anak muda Indonesia; kedua, merekatkan persaudaraan lintas komunitas anak muda Indonesia; Ketiga, mengajak generasi muda untuk taat kepada agama; terakhir menjadi wadah positif yang menampung hobi dan bakat generasi muda. ${ }^{29}$

\footnotetext{
${ }^{28}$ https://www.instagram.com/p/B4UBfxaFxoG/ (diakses 20 Oktober 2020)

${ }^{29} \mathrm{https}: / /$ www.instagram.com/p/B4mG-POFxJy/ (diakses 20 Oktober 2020)
} 


\section{Pembahasan dan Analisis Data}

Melalui pendekatan Semiotika Rolland Barthes, penelti mencoba menganalisis poster-poster yang diunggah pada akun Instagram @pesan_trend yang berfokus pada representasi anak muda Muslim. Adapun gambar-gambar yang merepresentasikan anak muda Muslim adalah sebagai berikut:

\section{Gambar 1.}

\section{Postingan@pesan_trend mengenai ajakan untuk berinfak}

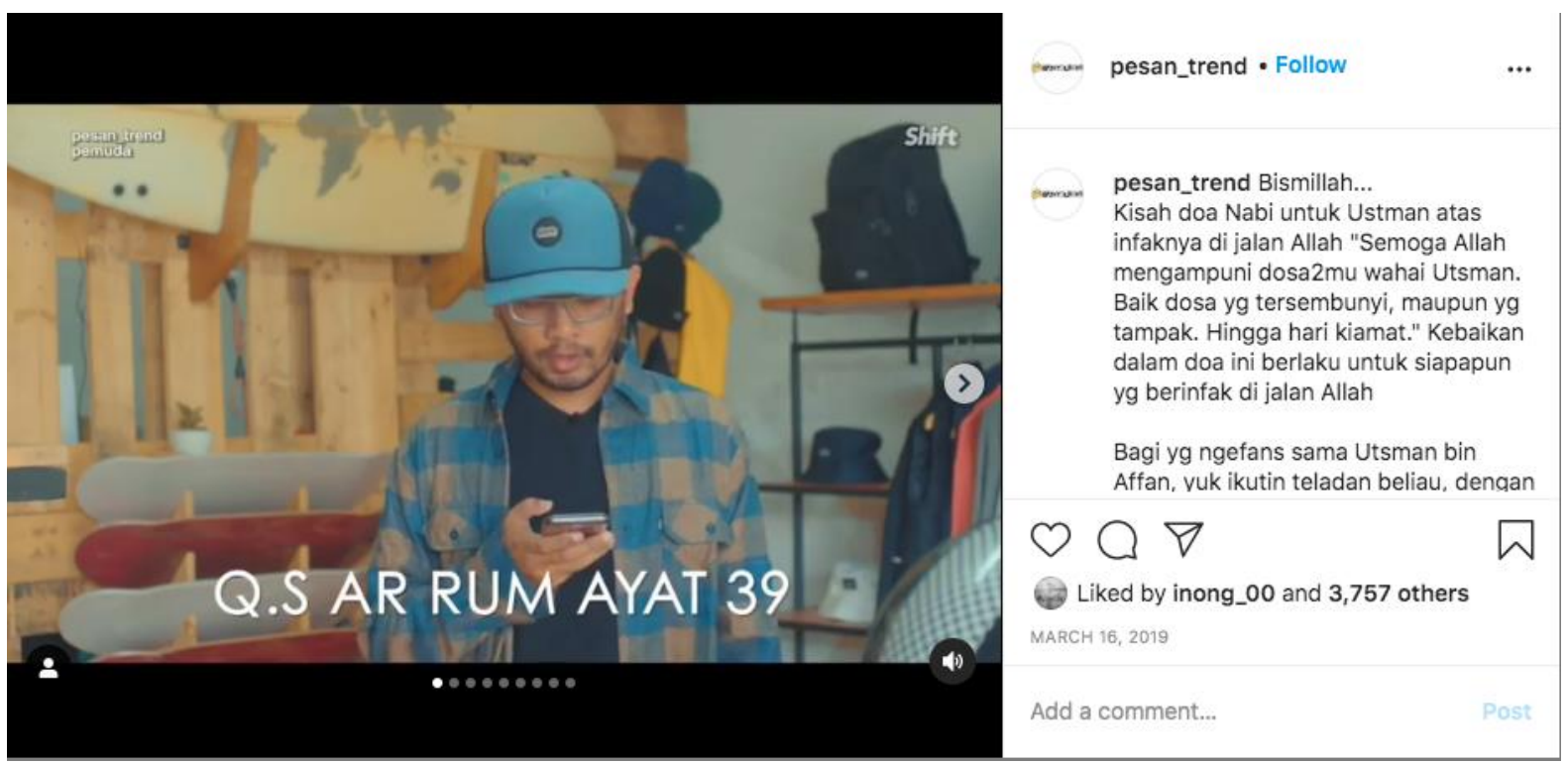

Sumber: Akun Instagram @pesan_trend

Dari gambar pertama ini terdapat beberapa makna. Secara denotasi video ini menunjukkan seorang UHA sedang menyampaikan pesan al-Qur'an dengan menggunakan pakaian kemeja flannel, kaos, dan topi dengan latar belakang beberapa produk distro, papan skateboard dan juga satu papan surfing. Namun secara konotasi menunjukkan bahwa dakwah yang dilakukan oleh UHA dan @pesan_trend menyasar anak muda. Secara mitos gambar ini menunjukkan bahwa dakwah tidak harus menggunakan pakaian yang serba Islami tetapi boleh juga dengan pakaian yang lain, dalam hal ini pakaian distro yang kental dengan budaya anak muda. Hal ini juga berkaitan dengan istilah 'lisani qoumihi', yang sering disampaikan UHA dalam ceramahnya, bahwa dakwah semacam ini merupakan upaya dakwah yang mungkin 
dapat diterima oleh anak muda. Dalam komunikasi, penggunaan pakaian termasuk ke dalam bahasa non-verbal, yang menunjukkan identitas baik itu identitas kelas, gender, usia dll. Dalam semiotika sosial pemilihan sumber-sumber visual menjadi sangat berarti, seperti mengapa seseorang memilih pakaian tertentu, menunjukkan makna tertentu yang ingin disampaikan si pembuat pesan. ${ }^{30}$ Dalam hal ini pakaian yang digunakan oleh UHA mencoba menjawab anggapan di kalangan anak muda bahwa untuk menjadi saleh, seseorang akan kehilangan nilai keanakmudaannya. Dan melalui gaya berpakaian UHA yang sangat mengikuti gaya fashion anak muda, menolak anggapan itu.

\section{Gambar 2.}

\section{Postingan @pesan_trend berjudul ‘Mari Kita Cerita tentang Shift Activity’}

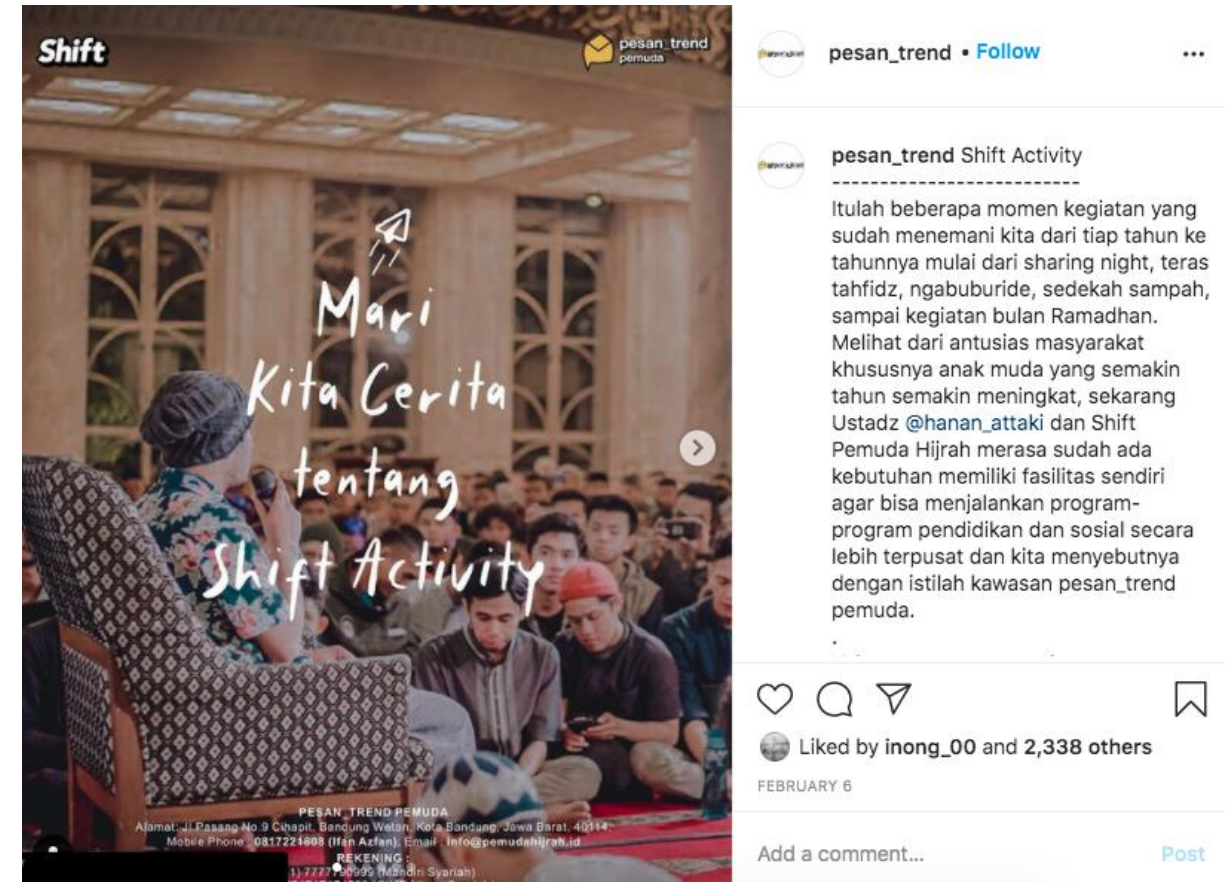

Sumber: Akun Instagram @pesan_trend

Secara denotasi poster ini menunjukkan kegiatan dakwah UHA di hadapan para anak muda, yang dibumbui tulisan 'Mari Kita Cerita tentang Shift Activity'. Secara konotasi poster @pesan_trend menggunakan istilah dan juga jenis huruf dari

\footnotetext{
${ }^{30}$ Eriyanto, Metode Komunikasi Visual: Dasar-Dasar dan Aplikasi Semiotika Soial untuk Membedak Teks Gambar (Bandung: PT Remaja Rosdakarya, 2019), 10.
} 
sebuah film yang berjudul 'Nanti Kita Cerita tentang Hari Ini (NKTCH)'. Lebih jauh lagi di sini @pesan_trend menunjukkan bahwa mereka mengikuti tren (atau trend dalam bahasa Inggris) di kalangan anak muda saat itu yang sedang menggandrungi film NKTCH. Artinya secara isu, @pesan_trend benar-benar mengikuti pesan yang sedang tren di kalangan anak muda.

\section{Gambar 3.}

\section{Postingan tentang kegiatan Tarbiyah Alam}
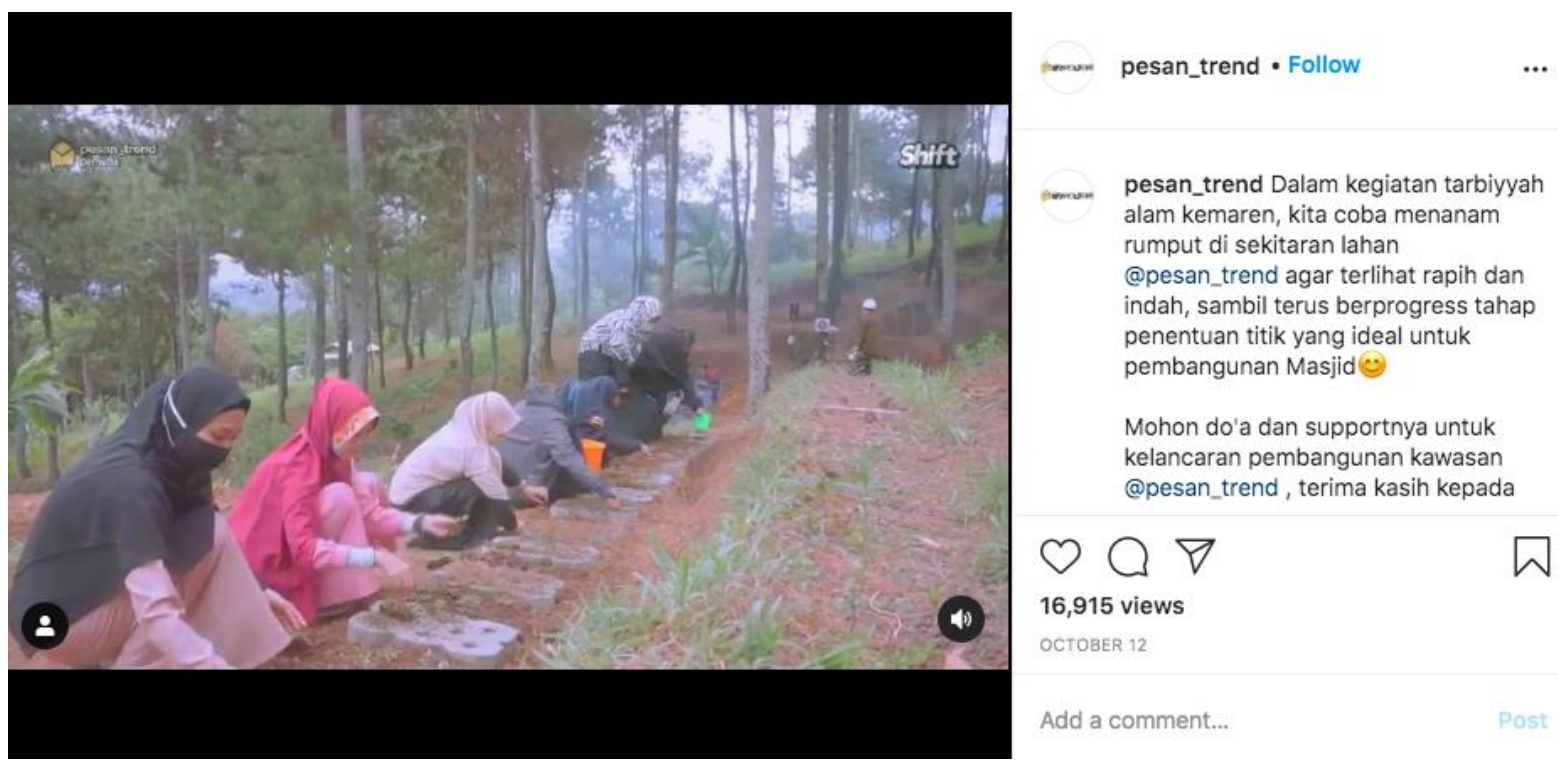

Sumber: Akun Instagram @pesan_trend

Secara denotasi, video ini menunjukkan beberapa wanita berhijab menanam rumput di sekitar hutan pinus. Secara konotasi @pesan_trend menyampaikan pesan mengenai pentingnya menjaga alam. Lebih dalam lagi hal ini berkaitan dengan wacana perubahan iklim (climate change). Bahwa dalam beberapa dekade terakhir isu kerusakan lingkungan menjadi salah satu isu yang hangat diperbincangkan. Kurangnya kesadaran mengenai lingkungan menjadi salah satu penyebab bumi yang semakin memanas. Hal ini juga seperti upaya menunjukkan bahwa di dalam agama Islam pun terdapat ajaran yang mengenai menjaga alam dan lingkungan. 
Representasi Anak Muda Gaul dan Saleh dalam Gerakan Hijrah: Analisis Semiotika Konten Akun Instagram Pesan Trend Pemuda (@pesan_trend)

\section{Kesimpulan}

Setelah meninjau dari segi denotasi, konotasi dan juga mitos konten akun Instagram @pesan_Trend menunjukkan representasi anak muda. Bahwa Gerakan dakwah di kalangan anak muda tidak bisa hanya dilihat dari kacamata orang dewasa melainkan harus juga melihat aspirasi anak muda yang aktif dalam memilah dakwah dan juga informasinya. Gerakan @pesan_trend yang dilakukan UHA dan Shift menunjukkan tindakan yang lebih aktif dari sekedar ceramah rutin di masjid, dengan melakukan kegiatan-kegiatan yang terkonsentrasi dalam waktu yang cukup lama.

Penggunaan pakaian distro, mengikuti tren film sampai dengan isu global yang dihadapi anak muda saat ini menunjukkan bahwa Pesan Trend Pemuda benarbenar menyampaikan pesan yang memang sedang tren di kalangan pemuda. Hal ini menjadi faktor penting bagaimana pesan dakwah diterima, karena ia menjadi in line dengan aspirasi yang dimiliki oleh komunikan.

\section{Daftar Pustaka}

Akmaliah, Wahyudi. “THE RISE OF COOL USTADZ: PREACHING, SUBCULTURES AND THE PEMUDA HIJRAH MOVEMENT." Dalam The new Santri: challenges to traditional religous authority in Indonesia. Singapore: ISEAS Publishing, 2020.

Bakti, Andi Faisal. "Raising Public Consciousness About the Importance of Freedom of Expression In Democratic Society and On Enhancing the Quality of Life of the Ordinary Citizen: the Case of Indonesia." The Journal of Development Communication 24, no. 1 (2013).

Bayat, Asef, dan Linda Herrera, ed. Being Young and Muslim: New Cultural Politics in The Global South and North. New York: Oxford University Press, 2010. 
Branston, Gill, dan Roy Stafford. The Media Student's Book. Fifth. Routledge, 2010. https://doi.org/10.4324/9780203850640.

Eriyanto. Metode Komunikasi Visual: Dasar-Dasar dan Aplikasi Semiotika Soial untuk Membedak Teks Gambar. Bandung: PT Remaja Rosdakarya, 2019.

Han, Muhamad Ibtissam. Dakwah Jalanan Kaum Muda: Dinamika Keagamaan Anak Muda Genk Motor dan Skateboard. Yogyakarta: Diandra Kreatif dan Penerbit Omah ilmu, 2019.

Han, Muhammad Ibtissam. "Ustadz Hits: Bahasa Gaul dan Social Media Effect." Dalam Islam: Antara Teks, Kuasa dan Identitas, disunting oleh Sunarwoto, 16381. Yogyakarta: Arti Bumi Intaran, 2018.

Hasan, Noorhaidi. “The Making of Public Islam: Piety, Agency, and Commodification on the Landscape of the Indonesian Public Sphere." Contemporary Islam 3, no. 3 (Oktober 2009): 229-50. https://doi.org/10.1007/s11562-009-0096-9.

Hefner, Robert W. Civil Islam: Muslims and Democratization in Indonesia. Princeton studies in Muslim politics. Princeton: NJ: Princeton University Press, 2000.

Heryanto, Ariel. Identitas dan Kenikmatan: Politik Budaya Layar Indonesia. Jakarta: Kepustakaan Populer Gramedia, 2015.

Kailani, Najib. "Forum Lingkar Pena and Muslim Youth in Contemporary Indonesia." Review of Indonesian and Malaysian Affairs 46, no. 1 (2012): 33-53.

- - - "Perkembangan Literatur Islamisme Populer di Indonesia: Apropriasi, Adaptasi dan Genre." Dalam Literatur Keislaman Generasi Milenial: Transmisi, Apropriasi, dan Kontestasi, disunting oleh Noorhaidi Hasan, 143-72. Yogyakarta: Pascasarjana UIN Sunan Kalijaga Press, 2018.

Lim, Merlyna. "Many Clicks but Little Sticks: Social Media Activism in Indonesia." Journal of Contemporary Asia 43, no. 4 (November 2013): 636-57. https://doi.org/10.1080/00472336.2013.769386.

Muzakki, Akh. “TRANSMITTING ISLAM THROUGH STORIES: The Sociology of Production and Consumption of Islam in Novel Literature." JOURNAL OF 
Representasi Anak Muda Gaul dan Saleh dalam Gerakan Hijrah: Analisis Semiotika Konten Akun Instagram Pesan Trend Pemuda (@pesan_trend)

INDONESIAN ISLAM 11, no. $1 \quad$ (6 Juli 2017): 59. https://doi.org/10.15642/JIIS.2017.11.1.59-76.

Nasir, Kamaludeen Mohamed. Globalized Muslim Youth in the Asia Pacific: Popular Culture in Singapore and Sydney. The Modern Muslim World. Basingstoke: Palgrave Macmillan, 2016.

Nisa, Eva F. "Creative and Lucrative Da 'wa: The Visual Culture of Instagram amongst Female Muslim Youth in Indonesia." Asiascape: Digital Asia 5, no. 1-2 (14 Februari 2018): 68-99. https://doi.org/10.1163/22142312-12340085.

Nisa, Eva F., dan Monika Arnez. “Dimensions of Morality: The Transnational Writers' Collective Forum Lingkar Pena." Bijdragen Tot de Taal-, Land- En Volkenkunde I Journal of the Humanities and Social Sciences of Southeast Asia 172, no. 4 (1 Januari 2016): 449-78. https://doi.org/10.1163/22134379-17204003.

Rakhmani, Inaya. Mainstreaming Islam in Indonesia. New York: Palgrave Macmillan US, 2016. https://doi.org/10.1057/978-1-137-54880-1.

Rosyad, Rifki. A Quest for True Islam: A Study of the Islamic Resurgence Movement among the Youth in Bandung, Indonesia. ANU E Press, 2007.

Sarkissian, Margaret. “'Religion Never Had It so Good': Contemporary Nasyid and the Growth of Islamic Popular Music in Malaysia." Yearbook for Traditional Music 37 (2005): 124-52.

Triantoro, Dony Arung. “D’RISE Magazine: Between The Piety, Popular Culture And Ideology," 2018, 31-40. 
Muhamad Ibtissam Han

120 | El Madani: Jurnal Dakwah dan Komunikasi Islam | Volume 2 No. 01 Tahun 2021, Hal. 101-120 